Original Research Article

\title{
A drug utilization study of antidepressant drugs in a tertiary care hospital
}

\author{
Vasundhara Yerkade $^{1 *}$, Riyaz Ahmed Siddiqui ${ }^{2}$
}

${ }^{1}$ Final year MBBS student, ${ }^{2}$ Department of Pharmacology, NKP Salve Institute of Medical Sciences and Research Center, Nagpur, Maharashtra, India

Received: 23 March 2017 Accepted: 22 April 2017

\section{*Correspondence to:}

Ms. Vasundhara Yerkade, Email: yerkadevasundhara@ gmail.com

Copyright: (C) the author(s), publisher and licensee Medip Academy. This is an openaccess article distributed under the terms of the Creative Commons Attribution NonCommercial License, which permits unrestricted noncommercial use, distribution, and reproduction in any medium, provided the original work is properly cited.

\begin{abstract}
Background: In psychiatric practice, antidepressant drugs are widely used group of drugs. Number of drugs are available in this group with diverse type of mechanisms and efficacy/safety profile. The objective for the study was to identify the prescribing pattern of antidepressant drugs in psychiatric patients at a tertiary care hospital and to see the distribution of antidepressant drugs in the sociodemographic group.

Methods: It was a record based descriptive study which was carried out at NKP Salve Institute of Medical Sciences and Research Centre, Nagpur. Case record files of all the patients suffering from depression and other psychiatric disorders and treated with antidepressant drugs during the period of from 1st January 2015 to 31 st December 2015 by institutional psychiatrists were analyzed for prescription pattern of antidepressant drugs and their age and sex wise distribution.

Results: A total no. of 300 patients received antidepressant drugs. The most commonly prescribed drug was escitalopram in $121(40.3 \%)$ patients followed by fluoxetine in $61(20.3 \%)$ and clomipramine in $30(10 \%)$ patients. Other drugs that were prescribed were mirtazapine in $24(8 \%)$, nortryptiline in $21(7 \%)$, venlafaxine in $13(4.3 \%)$, fluvoxamine in $12(4 \%)$, amitryptiline in $9(3 \%)$, dothiepin in $5(1.6 \%)$ and duloxetine in $4(1.3 \%)$ patients. Also patients in the age group of 31-40 yrs and 21-30 yrs received most number of antidepressants i.e. $129(40.3 \%)$ and $83(27.6 \%)$ patients respectively. Females have received more antidepressant drugs as compared to males.

Conclusions: Selective Serotonin Reuptake Inhibitors (SSRIs) are the most commonly prescribed group of antidepressant drugs. Escitalopram followed by Fluoxetine were the most commonly prescribed drugs for the management of depression and other psychiatric disorders because of their better efficacy, safety, tolerability and less side effects as compared to TCAs. Females suffer more from depression and other psychiatric disorders as compared to males and the most vulnerable is 21 to 40 yrs of age.
\end{abstract}

Keywords: Antidepressant, Selective serotonin reuptake inhibitors, Serotonin norepinephrine reuptake inhibitors, Tricyclic antidepressants

\section{INTRODUCTION}

Major depressive disorder (MDD) represents one of the most common causes of disability in the developed world. In addition major depression is associated with a variety of medical conditions from chronic pain to coronary artery disease. ${ }^{1}$ Depressive episodes are characterized by depressed or sad mood, pessimistic worry, diminished interest in normal activities, mental slowing and poor concentration, insomnia or increased sleep, significant weight loss or weight gain due to altered eating activity or eating patterns, psychomotor agitation or retardation, feeling of guilt or worthlessness, decreased energy or libido occurring most days for a period of 2 weeks. ${ }^{2}$

Antidepressants (AD) as a class of drugs is used primarily in the management of depressive disorders and anxiety disorders. However, this class of drugs is also used for the management of eating disorders, impulse control disorders, enuresis, sexual dysfunction, aggression and some personality disorders. ${ }^{3}$ 
Antidepressant prescribing patterns have changed globally over the last few years, with conventional drugs like tricyclic antidepressants (TCAs) and monoamine oxidase inhibitors (MAO inhibitors) being gradually replaced by selective serotonin reuptake inhibitors (SSRIs) and novel antidepressants. ${ }^{4}$

The World Health Organisation (WHO) defines drug utilization as the marketing, distribution, prescription and the use of drugs in a society, with special emphasis on the resulting medical, social and economic consequences. ${ }^{5}$ Also according to $\mathrm{WHO}$, it is estimated that major depression would be the second most leading cause of disability in the world by $2020 .^{6}$ The sociodemographic factors of age, gender, marital status, education, and income have consistently been identified as important factors in explaining the variability in the prevalence of depression. Prevalence for depression has also been found to vary considerably based on gender. Women have nearly double to triple the prevalence rates for 12month depression compared to men. ${ }^{7}$ Also in one largescale, cross-sectional epidemiological study on Major depressive disorder (MDD) among urban and rural residents in Beijing found low family income and female sex, among others, as independent risk factors of MDD. ${ }^{8}$

There are so many classes of antidepressant drugs are available for the management of depression and other psychiatric disorders in a retrospective study done in a private hospital at Chennai which include 750 patient, SSRIs are favored as first line treatment in a first episode of depression and are prescribed more frequently because the side effects are better tolerated than the older drugs. ${ }^{9}$ The past decade has seen an increase in the number and type of antidepressants available to psychiatrists and other clinician's. It is important to better understand current prescribing practices and to find out if there is any association of antidepressant drug use with sociodemographic factors.

\section{Aims and objectives}

- To observe the prescribing pattern of antidepressant drugs in psychiatric patients at a tertiary care hospital.

- To see the distribution of antidepressant drugs in the sociodemographic group.

\section{METHODS}

It was a record based descriptive study which was carried out at NKP Salve Institute of Medical Sciences and Research Centre, Nagpur. Case record files of all the patients suffering from depression and other psychiatric disorders and treated with antidepressant drugs during the period of from $1^{\text {st }}$ January 2015 to $31^{\text {st }}$ December 2015 by institutional psychiatrists were analyzed for prescription pattern of antidepressant drugs and their sex and age wise distribution.
Prior the study permission from institutional ethics committee was sought. Patient information like name, age, sex, address, hospital registration no., diagnosis and antidepressant drugs received like tricyclic antidepressants (TCAs), selective serotonin reuptake inhibitors (SSRIs), serotonin norepinephrine reuptake inhibitors (SNRIs) and atypical antidepressants for depression and other psychiatric disorders was noted. Data collected was analyzed percentagewise.

\section{RESULTS}

We have analyzed a total no. of 300 hospital case record files of the department of psychiatry. Patients were prescribed various antidepressant drugs like TCAs, SSRIs, SNRIs and Atypical antidepressants for depression and other psychiatric disorders. The most commonly prescribed drug was escitalopram in 121 $(40.3 \%)$ patients followed by fluoxetine in 61 (20.3\%) and clomipramine in $30(10 \%)$ patients. Other drugs that were prescribed were mirtazapine in $24(8 \%)$, nortriptyline in 21 (7\%), venlafaxine in $13(4.3 \%)$, fluvoxamine in $12(4 \%)$, amitriptyline in $9(3 \%)$, dothiepin in $5(1.6 \%)$ and duloxetine in $4(1.3 \%)$ patients as depicted in Table 1.

Table 1: Depicting drug received by the patients suffering from depression and other psychiatric disorders and their percentage.

\begin{tabular}{|llll|}
\hline $\begin{array}{l}\text { S. } \\
\text { No }\end{array}$ & $\begin{array}{l}\text { Name of the } \\
\text { drug }\end{array}$ & $\begin{array}{l}\text { No. of patients } \\
(300)\end{array}$ & $\begin{array}{l}\text { \% of } \\
\text { patients }\end{array}$ \\
\hline 1 & Escitalopram & 121 & 40.3 \\
\hline 2 & Fluoxetine & 61 & 20.3 \\
\hline 3 & Clomipramine & 30 & 10 \\
\hline 4 & Mirtazapine & 24 & 8 \\
\hline 5 & Nortriptyline & 21 & 7 \\
\hline 6 & Venlafaxine & 13 & 4.3 \\
\hline 7 & Fluvoxamine & 12 & 4 \\
\hline 8 & Amitriptyline & 9 & 3 \\
\hline 9 & Dothiepin & 5 & 1.6 \\
\hline 10 & Duloxetine & 4 & 1.3 \\
\hline
\end{tabular}

Also, it was observed that major depression was the most common psychiatric diagnosis among the patients i.e. in $94(31.3 \%)$ patients, followed by somatoform disorders in $51(17.3 \%)$, mixed anxiety and depression in $36(12 \%)$ and schizophrenia with depression in $35(11.6 \%)$ of patients among the top four diagnoses. The distribution of the primary psychiatric diagnoses of the patients and their percentage who received antidepressants was shown in Table 2.

Also it was observed that females have received more antidepressant drugs as compared to males i.e. 170 $(56.6 \%)$ and $130(43.3 \%)$ patients respectively, with escitalopram, clomipramine and fluoxetine being the most commonly prescribed drugs as seen in Table 3. 
Table 2: Depicting the primary psychiatric diagnoses of the patients and their percentage.

\begin{tabular}{|lll|}
\hline Diagnosis & $\begin{array}{l}\text { No. of patients } \\
(300)\end{array}$ & $\begin{array}{l}\text { \% of } \\
\text { patients }\end{array}$ \\
\hline Major Depression & 94 & 31.3 \\
\hline $\begin{array}{l}\text { Mixed anxiety and } \\
\text { depression }\end{array}$ & 36 & 12 \\
\hline $\begin{array}{l}\text { Schizophrenia with } \\
\text { depressive features }\end{array}$ & 35 & 11.6 \\
\hline Bipolar mood disorder & 16 & 5.3 \\
\hline $\begin{array}{l}\text { Obsessive compulsive } \\
\text { disorder }\end{array}$ & 24 & 8 \\
\hline Somatoform disorder & 51 & 17.3 \\
\hline Dissociative disorder & 8 & 2.6 \\
\hline Panic disorder & 9 & 3 \\
\hline $\begin{array}{l}\text { Acute and transient } \\
\text { psychotic disorder }\end{array}$ & 8 & 2.6 \\
\hline Alcohol dependence & 19 & 9.6 \\
\hline
\end{tabular}

Also it was observed that most number of patients who have received antidepressant drugs were in the age group of $31-40 y$ rs i.e. $129(40.3 \%)$ patients followed by 83 $(27.6 \%)$ patients in the age group 21-30 and $58(22.6 \%)$ patients in the 41-50 age group. Age group 61-70 yrs received the least number of antidepressant drugs as shown in Table 4.

Table 3: Depicting the antidepressant drug prescription according to sex of the patient.

\begin{tabular}{|llll|}
\hline $\begin{array}{l}\text { Antidepressant } \\
\text { drugs }\end{array}$ & $\begin{array}{l}\text { No. of } \\
\text { patients } \\
(300)\end{array}$ & $\begin{array}{l}\text { Gender } \\
\text { Female } \\
\mathbf{( 1 7 0 )}\end{array}$ & $\begin{array}{l}\text { Male } \\
(\mathbf{1 3 0})\end{array}$ \\
\hline Escitalopram & $\begin{array}{l}121 \\
(40.3 \%)\end{array}$ & $\begin{array}{l}66 \\
(38.8 \%)\end{array}$ & $55(42.3 \%)$ \\
\hline Fluoxetine & $\begin{array}{l}61 \\
(20.3 \%)\end{array}$ & $\begin{array}{l}37 \\
(21.7 \%)\end{array}$ & $24(18.4 \%)$ \\
\hline Clomipramine & $30(10 \%)$ & $\begin{array}{l}18 \\
(10.5 \%)\end{array}$ & $12(9.23 \%)$ \\
\hline Mirtazapine & $24(8 \%)$ & $15(8.8 \%)$ & $9(6.92 \%)$ \\
\hline Nortryptiline & $21(7 \%)$ & $11(6.4 \%)$ & $10(7.69 \%)$ \\
\hline Venlafexine & $13(4.3 \%)$ & $6(3.5 \%)$ & $7(5.38 \%)$ \\
\hline Fluoxamine & $12(4 \%)$ & $7(4.1 \%)$ & $5(3.84 \%)$ \\
\hline Amitryptiline & $9(3 \%)$ & $5(2.9 \%)$ & $4(3.07 \%)$ \\
\hline Dothiepine & $5(1.6 \%)$ & $3(1.7 \%)$ & $2(1.53 \%)$ \\
\hline Duloxetine & $4(1.3 \%)$ & $2(1.1 \%)$ & $2(1.53 \%)$ \\
\hline
\end{tabular}

Table 4: Depicting antidepressant drug prescription according to age of the patient.

\begin{tabular}{|ll|lllll|}
\hline Name of drug & No. of patients & Age in years & & & & \\
& $\mathbf{2 1 - 3 0}$ & $\mathbf{3 1 - 4 0}$ & $\mathbf{4 1 - 5 0}$ & $\mathbf{5 1 - 6 0}$ & $\mathbf{6 1 - 7 0}$ \\
\hline Escitalopram & $121(40.3 \%)$ & $33(39.7 \%)$ & $52(40.94 \%)$ & $22(39.2 \%)$ & $10(41.6 \%)$ & $4(40 \%)$ \\
\hline Fluoxetine & $61(20.3 \%)$ & $18(21.6 \%)$ & $24(18.89 \%)$ & $12(21.4 \%)$ & $5(20.8 \%)$ & $2(20 \%)$ \\
\hline Clomipramine & $30(10 \%)$ & $8(9.6 \%)$ & $12(9.44 \%)$ & $7(12.5 \%)$ & $2(8.3 \%)$ & $1(10 \%)$ \\
\hline Mirtazapine & $24(8 \%)$ & $6(7.2 \%)$ & $11(8.66 \%)$ & $4(7.1 \%)$ & $2(8.3 \%)$ & $1(10 \%)$ \\
\hline Nortryptiline & $21(7 \%)$ & $6(7.2 \%)$ & $9(7.08 \%)$ & $4(7.150$ & $2(8.3 \%)$ & $0(0 \%)$ \\
\hline Venlafexine & $13(4.3 \%)$ & $3(3.6 \%)$ & $6(4.72 \%)$ & $2(3.5 \%)$ & $1(4.1 \%)$ & $1(10 \%)$ \\
\hline Fluoxamine & $12(4 \%)$ & $4(4.8 \%)$ & $5(3.93 \%)$ & $1(1.7 \%)$ & $1(4.1 \%)$ & $0(0 \%)$ \\
\hline Amitriptyline & $9(3 \%)$ & $2(2.4 \%)$ & $4(3.14 \%)$ & $2(3.5 \%)$ & $0(0 \%)$ & $1(10 \%)$ \\
\hline Dothiepine & $5(1.6 \%)$ & $2(2.4 \%)$ & $2(1.57 \%)$ & $1(1.7 \%)$ & $1(4.1 \%)$ & $0(0 \%)$ \\
\hline Duloxetine & $4(1.3 \%)$ & $1(1.2 \%)$ & $2(1.57 \%)$ & $1(1.7 \% 0$ & $0(0 \%)$ & $0(0 \%)$ \\
\hline & 300 & 83 & 127 & 56 & 24 & 10
\end{tabular}

\section{DISCUSSION}

In the present study escitalopram was the most commonly used antidepressant drug in $121(40.3 \%)$ patients followed by fluoxetine in $61(20.3 \%)$ and clomipramine in $30(10 \%)$ patients. Other drugs that were prescribed were mirtazapine in $24(8 \%)$, nortryptiline in $21(7 \%)$, venlafaxine in $13(4.3 \%)$, fluvoxamine in $12(4 \%)$, amitryptiline in $9(3 \%)$, dothiepin in $5(1.6 \%)$ and duloxetine in $4(1.3 \%)$ of patients. Pinto et al evaluated tolerability and response to escitalopram in Indian patients with major depression in an 8-week open-label multicentric study among 18-65 years old found that escitalopram was well tolerated, with only 2 patients (1.7\%) withdrawing from the study due to adverse events. ${ }^{10}$ Piparva et al in a prospective cross sectional study of 6 months in outpatient psychiatric patients found that prescribing frequency of SSRIs $(36.66 \%)$ was more than the TCA $(21.96 \%)$ and atypical antidepressant drugs $(1.83 \%)$ in major depression. ${ }^{11}$ Grover et al in a multicentric study analyzed prescription data of 706 patients with first episode depression in diverse settings including teaching institutions in public and private sectors and even privately run psychiatric clinics found that escitalopram was the most commonly prescribed antidepressant, comprising $40 \%$ of the total prescriptions. This was followed by sertraline $(17.6 \%)$ and fluoxetine $(16.3 \%)$. In total SSRIs formed $79.2 \%$ of all the prescriptions. ${ }^{12}$ Tripathi et al in a multicentric investigator initiated research study conducted at five tertiary care 
psychiatric facilities of India at Lucknow, Chandigarh, Tiruvalla, Mumbai and Guwahati, which included 312 patients who attended outpatients department or were admitted in the psychiatry wards and who were using or had been prescribed antidepressant medications, found that a total of $194(62.2 \%)$ patients were using SSRIs with escitalopram $114(36.53 \%)$ being the most common antidepressant used. Overall, $272(87.18 \%)$ patients were using newer antidepressants. ${ }^{13}$ Boulenger JP et al compared efficacy of long-term treatment with escitalopram and paroxetine in severely depressed patients and found that escitalopram as significantly more effective than paroxetine in the long-term treatment of severely depressed patients. ${ }^{14}$ The above studies indicate that use of SSRIs is much more common in comparison to other group of antidepressant drug for the management of depression and other psychotic disorders. Findings of other authors about superiority of escitalopram are similar to our observations as we also found use of escitalopram as most common. SSRI are generally free of sedative effects and safer at higher doses. Better tolerability, combined with their mild adverse effects, accounts for their popularity as most widely prescribed antidepressants. ${ }^{11}$

Banerjee et al in a hospital based observational study between $1^{\text {st }}$ October 2009 and $31^{\text {st }}$ March 2010 at psychiatry ward of a teaching hospital, among the 240 psychiatric patients found fluoxetine, the commonest antidepressants to be prescribed $42.1 \%$ followed by amitriptyline $26.3 \%$, trazodone $21.1 \%$ etc. ${ }^{6}$ Mathur et al evaluated the anti-depressant efficacy of newer antidepressant mirtazapine as compared to amitryptiline and found that mirtazapine was effective in the treatment of major depression at the dosages range of 15-45 mg/day and it has efficacy equivalent to that of amitriptyline, with a better tolerability profile. ${ }^{15}$ In our study clomipramine was one of the commonly prescribed drug from the tricyclic group of antidepressants. In our study apart from depression it is mostly prescribed in cases obsessive compulsive disorder (OCD) and somatoform disorders. OCD is known to respond to serotonergic antidepressant. Clomipramine and several of the SSRIs are approved for the treatment of OCD and they are moderately effective. ${ }^{1}$

In our study depressive disorder was the most common psychiatric diagnosis among the population i.e. in 94 $(31.3 \%)$ patients, followed by somatoform disorders in 51 $(17.3 \%)$, mixed anxiety and depression in $36(12 \%)$ and schizophrenia with depression in $35(11.6 \%)$ of patients among the top four diagnoses. Previous research has found that age is one of the demographic characteristics that accounts for much of the variance in the prevalence of depression. Prevalence for depression has also been found to vary considerably based on gender and women have nearly double to triple the prevalence rates for 12month depression compared to men. ${ }^{7}$ Danesh et al observed that the highest prevalence rate of lifetime depression $(14.3 \%)$ is seen in the age group of 20 to 24 years and the lowest rate $(4.3 \%)$ in the age group of 75 years and over. ${ }^{16}$ In a study which reviewed 279737 prescriptions by general practitioners and psychiatrists in Iran it was observed that $3.1 \%$ of prescriptions included antidepressant drugs. Females receiving antidepressant drugs were $63.7 \%$ and males $36.3 \%$. Maximum prescription rate was for the age group of 30-39 years (28\%), while the lowest prescription rate belonged to the age groups of fewer than 10 years and over 80 years. ${ }^{17}$ Lahon et al in a retrospective, observational study analyzed the case records of patients who received antidepressant prescriptions at the Psychiatry outpatients clinic of a tertiary care hospital found that the majority of patients who received the antidepressants belonged to the 21-40 years age group. ${ }^{18}$ In our study also we have found that distribution of antidepressant drugs is more in female patients i.e. $170(56.6 \%)$ as compared to males i.e. 134 $(44.6 \%)$. It is likely that genetic, biological, chemical, hormonal, environmental, psychological and social factors all intersect to contribute to depression in women. ${ }^{19}$

The distribution of antidepressant drugs is more common. In the groups of 21-30 and 31-40 yrs age group i.e. $27.7 \%$ and $42.5 \%$ respectively. The least number of antidepressant are received by the elderly patients above $60 \mathrm{yrs}$ of age i.e. $10(3 \%)$ of patients, the findings are in accordance with the above studies.

\section{CONCLUSION}

SSRIs are the most commonly prescribed group of antidepressant drugs. Escitalopram followed and Fluoxetine were the most commonly prescribed drugs for the management of depression and other psychiatric disorders because of their better efficacy, safety, tolerability and less side effects as compared to TCAs. Females have received more antidepressant as compared to males and 21 to $40 \mathrm{yrs}$ age group received the most number of antidepressants.

\section{Funding: No funding sources Conflict of interest: None declared \\ Ethical approval: The study was approved by the Institutional Ethics Committee}

\section{REFERENCES}

1. De Battista C, Katzung B. Antidepressant agent. In: (Eds). Basic and Clinical Pharmacology $13^{\text {th }} \mathrm{Ed}$, New Delhi: Mc Graw Hill; 2015:510-530.

2. Donnell JM, Shelton RC. Drug therapy of depression and anxiety disorders. In: Goodman and Gilmans. The Pharmacological basis of therapeutics $12^{\text {th }} \mathrm{Ed}$, New Delhi: Mc Graw Hill; 397-45.

3. Avasthi A, Grover S, Aggarwal M. Research on antidepressants in India. Indian J Psychiatry. Jan 2010; 52(1):S341-54.

4. Memon A, Patel K. Drug use pattern of antidepressant agents in psychiatric patients: A 
prospective study. NHL Journal of Medical Sciences. 2013;2:2.

5. Schneeweiss S, Patrick AR, Solomon DH, Mehta J, Dormuth C, Miller M, et al. Variation in the Risk of Suicide Attempts and Completed Suicides by Antidepressant Agent in Adults. Arch Gen Psychiatry. 2010 May;67(5):497-506.

6. Banerjee I, Roy B, Banerjee I, Sathian B, Mondal M, Saha A. Depression and its Cure: A Drug Utilization Study from a Tertiary Care Centre of Western Nepal. Nepal Journal of Epidemiology. 2011;1(5).

7. Danesh NA, Landeen J. Relation between depression and sociodemographic factors. Mental Health Syst. 2007;1:4.

8. Chun-Lee T, Chiang YC, Huang JY, Tantoh DM, Nfor ON, Lee JF, et al. Incidence of Major Depressive Disorder: Variation by Age and Sex in Low-Income Individuals. Medicine (Baltimore). 2016 Apr;95(15):e3110.

9. Mohanta G, Manavalan R, Prabha K, Prasanna M. Retrospective utilization patterns of antidepressant medications. The Internet Journal of Third World Medicine. 2007;1.

10. Pinto C1, Trivedi JK, Vankar GK, Sharma PS, Narasimha V. An open-label multicentric study of the tolerability and response to escitalopram treatment in Indian patients with major depressive disorder. J Indian Med Assoc. 2007 Jul;105(7):364,366,368.

11. Piparva KG, Parmar DM, Singh AP, Gajera MV, Trivedi HR. Drug Utilization Study of Psychotropic Drugs in Outdoor Patients in a Teaching Hospital. Indian J Psychol Med. 2011 Jan-Jun;33(1):54-8.

12. Grover S, Avasth A, Kalita K, Dalal PK, Rao GP, Chadda RK, et al. IPS multicentric study: Antidepressant prescription patterns. Indian J Psychiatry. 2013 Jan-Mar;55(1):41-5.
13. Tripathi A, Avasthi A, Desousa A, Bhagabati D, Shah N, Kallivayalil RA, et al. Prescription pattern of antidepressants in five tertiary care psychiatric centres of India. Indian J Med Res. 2016 Apr;143(4):507-13.

14. Boulenger JP, Huusom AK, Florea I, Baekdal T, Sarchiapone M. A comparative study of the efficacy of long- term treatment with escitalopram and paroxetine in severely depressed patients. Curr Med Res Opin. 2006;22(7):1331-41.

15. Mathur A, Chowdhary A, Jain M. A comparative study of the efficacy and safety of mirtazapine versus amitriptyline in the treatment of major depression. Indian J Psychiatry. 2002 Jul;44(3):260-5.

16. Danesh NA, Landeen J. Relation between depression and sociodemographic factors. Int $\mathrm{J}$ Ment Health Syst. 2007;1:4.

17. Motevallyzadeh HR, Baneshi MR, Rameshk M, Nakhaee N. Prescribing Pattern of Antidepressant Drugs among General Practitioners and Psychiatrists: a study from Iran. Russian Open Medical Journal. 2013;2(2).

18. Lahon AK, Shetty HM, Paramel A, Sharma G. A Retrospective Drug Utilization Study of antidepressants in the Psychiatric unit of a Tertiary Care Hospital. Journal of Clinical and Diagnostic Research. 2011 October;5(5):1069-75 .

19. Bohra N, Srivastava S, Bhatia MS. Depression in women in Indian context. Indian J Psychiatry. 2015 Jul;57(2):S239-45.

Cite this article as: Yerkade V, Siddiqui RA. A drug utilization study of antidepressant drugs in a tertiary care hospital. Int J Basic Clin Pharmacol 2017;6:1405-9. 